\section{LMI1 homeodomain protein regulates organ proportions by spatial modulation of endoreduplication}

\author{
Francesco Vuolo, ${ }^{1}$ Daniel Kierzkowski, ${ }^{1,4}$ \\ Adam Runions, ${ }^{1}$ Mohsen Hajheidari, ${ }^{1}$ \\ Remco A. Mentink, ${ }^{1}$ Mainak Das Gupta, ${ }^{1}$ \\ Zhongjuan Zhang, ${ }^{1}$ Daniela Vlad, ${ }^{2}$ Yi Wang, ${ }^{1}$ \\ Ales Pecinka, ${ }^{3,5}$ Xiangchao Gan, ${ }^{1}$ Angela Hay, ${ }^{1}$ \\ Peter Huijser, ${ }^{1}$ and Miltos Tsiantis ${ }^{1}$

\begin{abstract}
${ }^{1}$ Deparment of Comparative Development and Genetics, Max Planck Institute for Plant Breeding Research, 50829 Cologne, Oxford OX1 3RB, United Kingdom; ${ }^{3}$ Department of Plant Breeding Genetics, Max Planck Institute for Plant Breeding Research, 50829 Cologne, Germany
\end{abstract} \\ Germany; ${ }^{2}$ Department of Plant Sciences, University of Oxford,
}

How the interplay between cell- and tissue-level processes produces correctly proportioned organs is a key problem in biology. In plants, the relative size of leaves compared with their lateral appendages, called stipules, varies tremendously throughout development and evolution, yet relevant mechanisms remain unknown. Here we use genetics, live imaging, and modeling to show that in Arabidopsis leaves, the LATE MERISTEM IDENTITY1 (LMI1) homeodomain protein regulates stipule proportions via an endoreduplication-dependent trade-off that limits tissue size despite increasing cell growth. LM1 acts through directly activating the conserved mitosis blocker WEE1, which is sufficient to bypass the LMI1 requirement for leaf proportionality.

Supplemental material is available for this article.

Received July 2, 2018; revised version accepted

September 21, 2018.

How spatiotemporal coordination of cell and tissue growth contributes to plant and animal form is a key question in biology. Plant leaves are a powerful system to study growth and form because they show complex and diverse geometries that can be studied genetically. Leaf growth typically involves a phase of cell proliferation early in development followed by cell expansion associated with endoreduplication (Melaragno et al. 1993). However, developmental inputs into endoreduplication and how these shape leaf form remain largely unknown (Walker

[Keywords: plant homeobox; leaf development; organ proportions; live imaging]

Present addresses: ${ }^{4}$ Institute de Recherche en Biologie Végétale, Université de Montréal, Montréal, QC H1X 2B2, Canada; ${ }^{5}$ Institute of Experimental Botany of the Czech Academy of Sciences (IEB), 77900 Olomouc-Holice, Czech Republic.

Corresponding author: tsiantis@mpipz.mpg.de

Article published online ahead of print. Article and publication date are online at http://www.genesdev.org/cgi/doi/10.1101/gad.318212.118. Freely available online through the Genes \& Development Open Access option. et al. 2000; Cookson et al. 2005; Massonnet et al. 2011). A key feature of leaf shape is the production of repeated marginal protrusions. These outgrowths vary from slight serrations in simple leaves to distinct leaflets in dissected leaves (Hay and Tsiantis 2006; Bilsborough et al. 2011; Hasson et al. 2011; Bar and Ori 2014; Vlad et al. 2014; Rast-Somssich et al. 2015). Stipules are another type of outgrowth that contribute considerably to macroevolutionary diversity in leaf form (Sinnott and Bailey 1914), a possibility also introduced by Darwin (1865); however, the mechanisms that influence stipule growth and development are poorly understood. Stipules typically flank the leaf base and vary in morphology from vestigial structures, as in Arabidopsis thaliana, to large leafy photosynthetic units, as in the pea. In A. thaliana, stipules initially comprise a significant proportion of the leaf primordium but only a small fraction of the mature leaf length (Fig. $1 \mathrm{~A}-\mathrm{C})$. This indicates strong allometric regulation of leaf versus stipule growth, the genetic basis of which is unknown.

\section{Results and Discussion}

To identify molecular mechanisms required to yield correctly proportioned leaves, we investigated the HD-ZIP class I transcription factor LATE MERISTEM IDENTITY1 (LMI1) (Saddic et al. 2006), which regulates leaf growth in A. thaliana (Vlad et al. 2014). LMI1 expresses in the distal leaf margin (Fig. 1D-F), where serrations fail to form in lmi1 mutant leaves (Fig. 1G; Supplemental Fig. 1A-F; Saddic et al. 2006; Vlad et al. 2014; Vuolo et al. 2016). Conversely, $L M I 1$ is not expressed in the proximal leaf margin (Fig. 1D-F), yet Imi1 leaves display ectopic lobes in this region of the leaf (Fig. 1G; Supplemental Fig. 1C, D,G-K; Saddic et al. 2006). The smooth distal margin of Imi1 leaves is consistent with LMIl acting as a growth repressor (Vlad et al. 2014); for example, mutations in the local growth repressors REDUCED COMPLEXITY (RCO) and CUP-SHAPED COTYLEDON 2 (CUC2) lead to smoother leaves (Bilsborough et al. 2011; Vlad et al. 2014). However, the lobed proximal margin of Imi1 leaves is difficult to reconcile with LMI1 function. Surprisingly, lobe formation in $1 m i 1$ does not require CUC2 or KNOTTED-LIKE HOMEOBOX (KNOX) gene function, which are known regulators of lobe development (Fig. 1G; Supplemental Fig. 1K; Lincoln et al. 1994; Bilsborough et al. 2011; Hasson et al. 2011; Rast-Somssich et al. 2015). LMI1 expresses in developing stipules (Fig. 1D,E), eventually becoming restricted to the proximal part of mature stipules (Fig. 1F). Therefore, we hypothesized that LMI1 may act in stipules to limit their growth, leading to their excess growth into lobes in the lmi1 mutant. In this case, genetic ablation of stipules should remove ectopic lobes in Imi1 leaves. To test this idea, we used a stipule-less mutant of WUSCHEL-RELATED HOMEOBOX 3 (WOX3) (Shimizu et al. 2009) and found no lobed margins in wox3-2;1mi1-2 double mutants (Fig. 1G), strongly suggesting that the lobed margin in lmi1 leaves results from a transformation of the stipule into a leaf.

(C) 2018 Vuolo et al. This article, published in Genes \& Development, is available under a Creative Commons License (Attribution 4.0 International), as described at http://creativecommons.org/licenses/by/4.0/. 


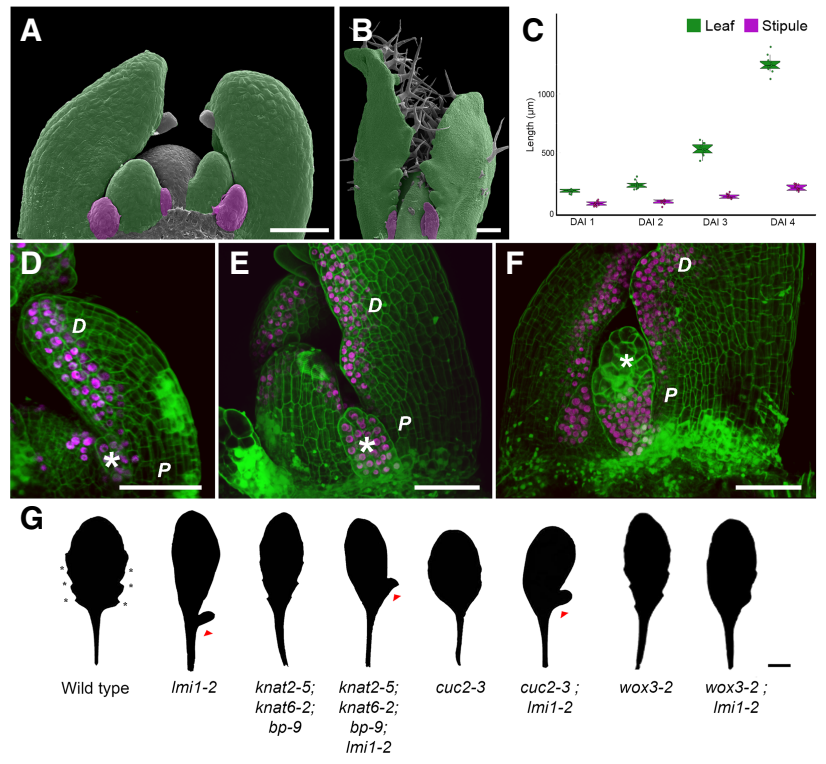

Figure 1. LATE MERISTEM IDENTITY1 (LMI1) is expressed in the distal leaf domain and stipule. $(A-C)$ Wild-type leaves (green) and stipules (purple) in false-colored scanning electron micrographs at $2 \mathrm{~d}$ after leaf initiation (DAI) $(A)$ and $8 \mathrm{DAI}(B)$ and length (in micrometers) at successive DAI $(C) . n=10$ leaves. Mean \pm SEM. $(D-F)$ Confocal laser scanning microscopy (CLSM) of LMI1::LMI1:VENUS expression (magenta) in propidium iodide (PI)-stained (green) leaf primordia at $3 \mathrm{DAI}(D), 5 \mathrm{DAI}(E)$, and $7 \mathrm{DAI}(F) . n=5$ independent $\mathrm{T} 2$ lines. (Asterisks) Stipules; (D) distal leaf domains; (P) proximal leaf domains. Bars: $A, B, D-F, 50 \mu \mathrm{m}$. (G) Silhouettes of adult leaves from wild-type and mutant plants. For penetrance scoring, see Supplemental Table 1. (Triangles) Ectopic lobes; (asterisks) serrations. Bar, $1 \mathrm{~cm}$.

To verify whether basal lobes of lmi1 mutants are overgrown stipules and investigate the cellular basis of this transformation, we performed time-lapse imaging of growing leaves (Fig. 2A-H; Barbier de Reuille et al. 2015). Wild-type stipules show high rates of cell proliferation and growth starting $1 \mathrm{~d}$ after leaf initiation (DAI) (Fig. $2 \mathrm{C}, \mathrm{E}, \mathrm{I})$. By $3 \mathrm{DAI}$, cell proliferation decreased dramatically, as did cell growth at $4 \mathrm{DAI}$ (Fig. 2C,E,I). In contrast, cell proliferation and growth were maintained for longer in lmi1 stipules, with cells still dividing at 5-6 DAI (Fig. 2D), leading to smaller cells in Imi1 than wild-type stipules (Fig. 2G,H,J). In addition, clonal sectors derived from lineage tracing analysis were considerably more elongated in Imi1 stipules (Supplemental Fig. 2A-D). Thus, growth is higher in lmi1 than wild-type stipules from 3 DAI onward and proceeds for longer (Fig. 2E,F,I). Growth rate and cell area correlate negatively in these tissues, indicating that tissue growth reduces as cells enlarge (Fig. 2K). This correlation was weaker for lmi1 than wildtype stipules, suggesting that its underlying mechanism requires $L M I 1$ (Fig. 2K).

Although LMI1 is expressed in at least two outer cell layers, stipules originate from epidermal founder cells (approximately one to five cells) (Supplemental Figs. 2A,C,E$\mathrm{G}, 3 \mathrm{~A}-\mathrm{C}$ ). In contrast, lmi1 stipules initiate from a larger number of founder cells (approximately seven to 12 cells epidermally) (Supplemental Fig. 3D-F) that can also include cells from internal layers (Supplemental Fig. 2H,I). This suggests that LMI1 represses stipule size at least in part by restricting stipule initial cells to the epidermis and limiting their number. We also observed stomata and trichome cells in lmi1 stipules, normally present only in the leaf and not in wild-type stipules (Fig. 2A,B). Therefore, in the absence of LMI1, more stipule initial cells are recruited to form a larger leaf-like outgrowth. In wild type, the stipule base is very narrow and stays attached to the boundary zone between the leaf base and adjacent tissue (Supplemental Fig. 2C). In contrast, the Imi1 stipule base grows together with adjacent petiole cells, progressively fusing the stipule with the leaf (Supplemental Figs. 1A-D, G-J, 2C,D). The extent of this fusion is variable, however, and the presence or absence of a lobe results from incomplete or complete fusion, respectively. The transformed stipules are more distally located (Fig. 1G) than their wild-type counterpart present at the leaf base, which is consistent with them initiating in a faster-growing context (Fig. 2E,F). Imi1 stipules also grow anisotropically, more akin to the leaf petiole than to wildtype stipules (Supplemental Fig. 2J-M). The length of Imi1 stipules reaches three times the length of wild-type stipules (Supplemental Fig. 4A,B), thus altering the allometric proportions of stipule to leaf in Imi1 leaves (Supplemental Fig. 4C,D). Overall, our findings suggest that LMI1 restricts stipule size by limiting founder cell recruitment and advancing cells from proliferative to expansive growth such that cell size increases but tissue growth is reduced.

Endoreduplication counters cell proliferation, promotes cell enlargement, and can influence cell identity (Szymanski and Marks 1998; Bramsiepe et al. 2010; Maruyama et al. 2011; Roeder et al. 2012); therefore, we hypothesized that LMI1 might affect cell division, cell size, and organ identity in the stipule by promoting endoreduplication. Comparing DNA ploidy levels in wild-type, lmi1, and broadly expressing 35 S::LMI1 plants (Fig. 3A), we found that the lmi1 mutant has $27 \%$ more $2 \mathrm{C}$ nuclei but $35 \%$ less 4C nuclei and $50 \%$ less $8 \mathrm{C}$ nuclei compared with wild type. In contrast, the $35 S:: L M I 1$ transgenic line shows almost $150 \%$ more $8 \mathrm{C}$ nuclei and $30 \%$ less $2 \mathrm{C}$ nuclei than wild-type samples. These observations indicate that $L M I 1$ is necessary and sufficient to define the wild-type leaf endoreduplication profile (Fig. 3A). Consistent with these findings, leaf trichomes were excessively branched in $35 \mathrm{~S}:$ : LMI1 compared with wild type (Supplemental Fig. 5), a phenotype linked to increased endoreduplication (Walker et al. 2000). Additionally, we found that cell size and polytene regions (fused sister chromatids that form after endoreduplication) were reduced in the stipules and leaf margin of 1 mi1 (Supplemental Fig. 6), further indicating that LMI1 promotes endoreduplication in the leaf base. To explore cellular processes influenced by LMI1 at the whole-genome level, we used RNA sequencing (RNA-seq) to compare wild-type and lmi1 seedling transcriptomes. We found that differentially expressed genes were enriched for gene ontology $(\mathrm{GO})$ terms related to the cell cycle, cell growth, and DNA replication (Fig. 3B), consistent with LMI1 promoting endoreduplication.

One of the key cell cycle genes showing reduced expression in Imi1 is WEE1 (Fig. 3C), which can inhibit mitosis, may promote endoreduplication (De Schutter et al. 2007; Gonzalez et al. 2007; Chevalier et al. 2011), and is expressed in both leaves and stipules (Supplemental Fig. 7). WEE1 is likely to be a direct target of LMI1, as it is transcriptionally up-regulated upon treatment with dexamethasone and the protein synthesis inhibitor cycloheximide in plants harboring a glucocorticoid-inducible LMI1 transgene (LMI1::LMI1-GR) (Fig. 3D). Consistent with 

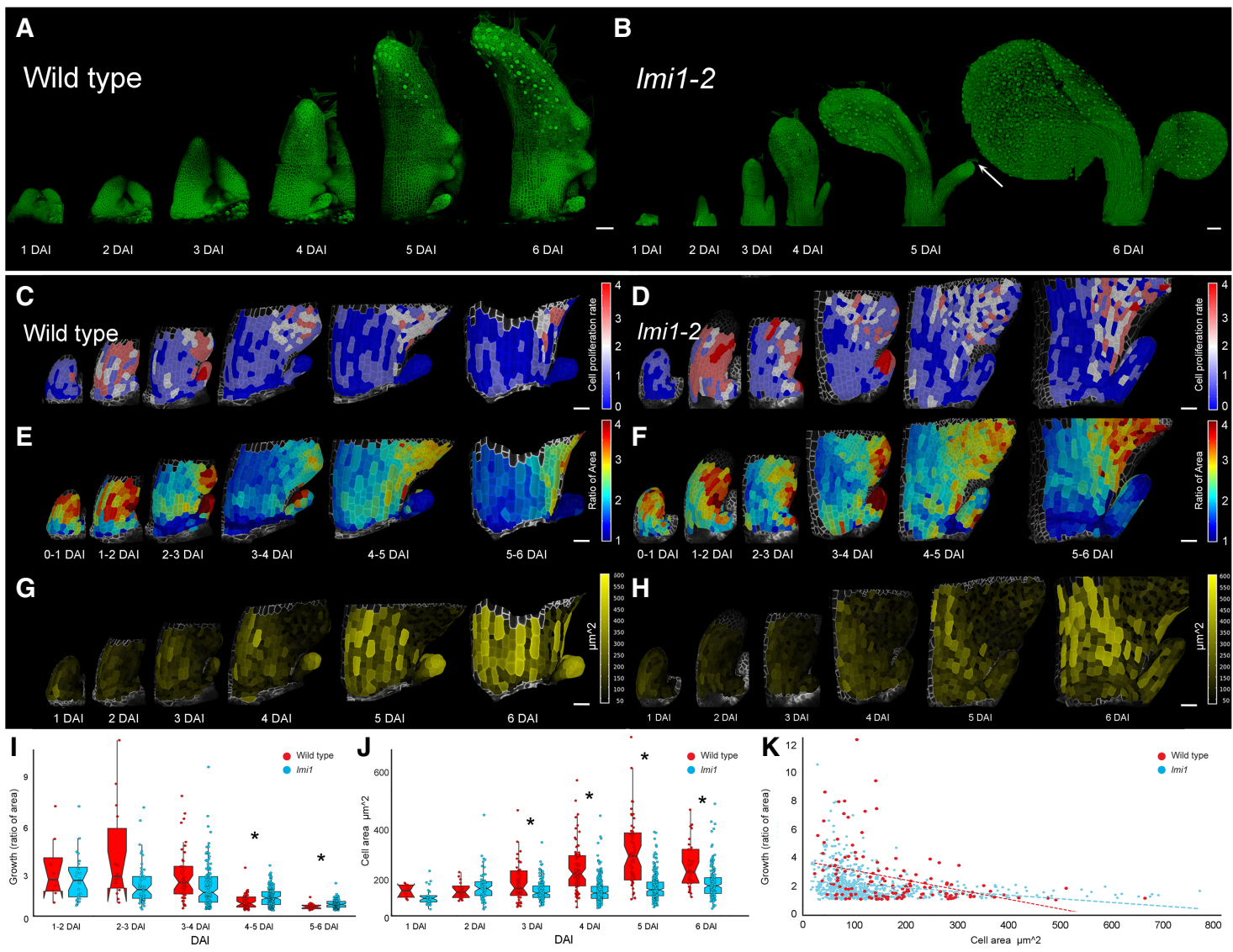

Figure 2. LMI1 represses tissue growth and cell proliferation in stipules. $(A, B)$ Time-lapse CLSM of leaf 11 developing over 1-6 DAI in wild type $(A)$ and lmi1-2 $(B)$. Cells are outlined by PM-YFP expression. (Arrow) Trichome. $(C-H)$ Cell proliferation rate (number of divisions; $C, D)$, growth (ratio of areas; $E, F)$, and cell area $(G, H)$ quantified in wild-type $(C, E, G)$ and $l m i 1-2(D, F, H)$ leaf 11 time-lapse series. Scales are shown in heat maps. $n=5$. $(I, J)$ Quantification of cell growth (ratio of areas; $I$ ) and area (square micrometers; $J$ ) in wild-type (red) and 1 mi1-2 (blue) leaf $11 . n=3$ timelapse series; $n>50$ cells. Mean \pm SD. $\left({ }^{*}\right) P<0.05$, KS-test $(I)$ and Student's $t$-test $(J)$. $(K)$ Cell area and growth values pooled for all DAI in wild-type (red; $n=139$ cells) and lmi1-2 (blue; $n=690$ cells) leaf 11 . Dashed lines represent linear regressions. Bars: $A-H, 50 \mu \mathrm{m}$.

this idea, we amplified WEE1 regulatory regions from chromatin immunoprecipitated using anti-GFP and found enrichment of LMI1:VENUS at two regions with predicted LMI1-binding sites (CAATwAT, where w is A or T) (Fig. 3E; Franco-Zorrilla et al. 2014). To determine whether WEE1 is critical for LMI1 function, we expressed LMI1:: WEE1 in Imi1 mutants, which restored wild-type leaf shape, indicating that WEE1 expression suffices to bypass the requirement for LMI1 in leaf development (Fig. 3F,G). Although wee1 mutant leaves resemble wild type (De Schutter et al. 2007), this background was sufficient to ameliorate the growth repression caused by $35 S:: L M I 1$ (Vlad et al. 2014), underscoring the importance of WEE1 for LMI1 function (Supplemental Fig. 8). These findings suggest that $L M I 1$-dependent endoreduplication regulates leaf form by locally restricting cell proliferation. To further test this idea, we expressed LMI1::CCS52, a known regulator of endoreduplication that is LMI1-independent (Fig. 3F; Cebolla et al. 1999), and found it sufficient to rescue both the lobed leaf and serration phenotype of Imi1 mutants (Fig. 3F,G). In addition, 35S::LMI1 plants developed smaller leaves (Supplemental Figs. 5A, 8D; Vlad et al. 2014). These results indicate that activating endoreduplication may limit final organ size. However, these findings are in contrast to previous reports showing that endoreduplication is associated with increased organ size in fruits and leaves (Melaragno et al. 1993; Gonzalez et al. 2007; Chevalier et al. 2011; Massonnet et al. 2011). We hypothesized that the interplay between cell proliferation and endoreduplication and the relative timing of their activation may be critical to determine final organ size. To formally examine this possibility, we constructed a minimal cell population model (Fig. 4A,B; Supplemental Fig. 9A,B; see the Supplemental Material for details). This model relates organ size to the timing of proliferation and endoreduplication within a finite window preceding differentiation. The model shows that endoreduplication leads to an increase in organ size except when activated very early. In this case, the decrease in cell number cannot be compensated for by the increase in cell size resulting from endoreduplication (Fig. 4B; Supplemental Fig. 9C, D). These results show that the timing of cells switching from proliferation to endoreduplication is critical and that early activation of endoreduplication may significantly reduce organ size.

By exploring the model's parameter space, we found that the start time of endoreduplication should have the largest effect on organ size in the context of highly proliferative tissues (i.e., when $R_{S}$ is large) (Supplemental Fig. 9D). In proliferative tissues, endoreduplication reduces cell division and, ultimately, cell number. For highly proliferative tissues, this loss exceeds what can be 
Vuolo et al.
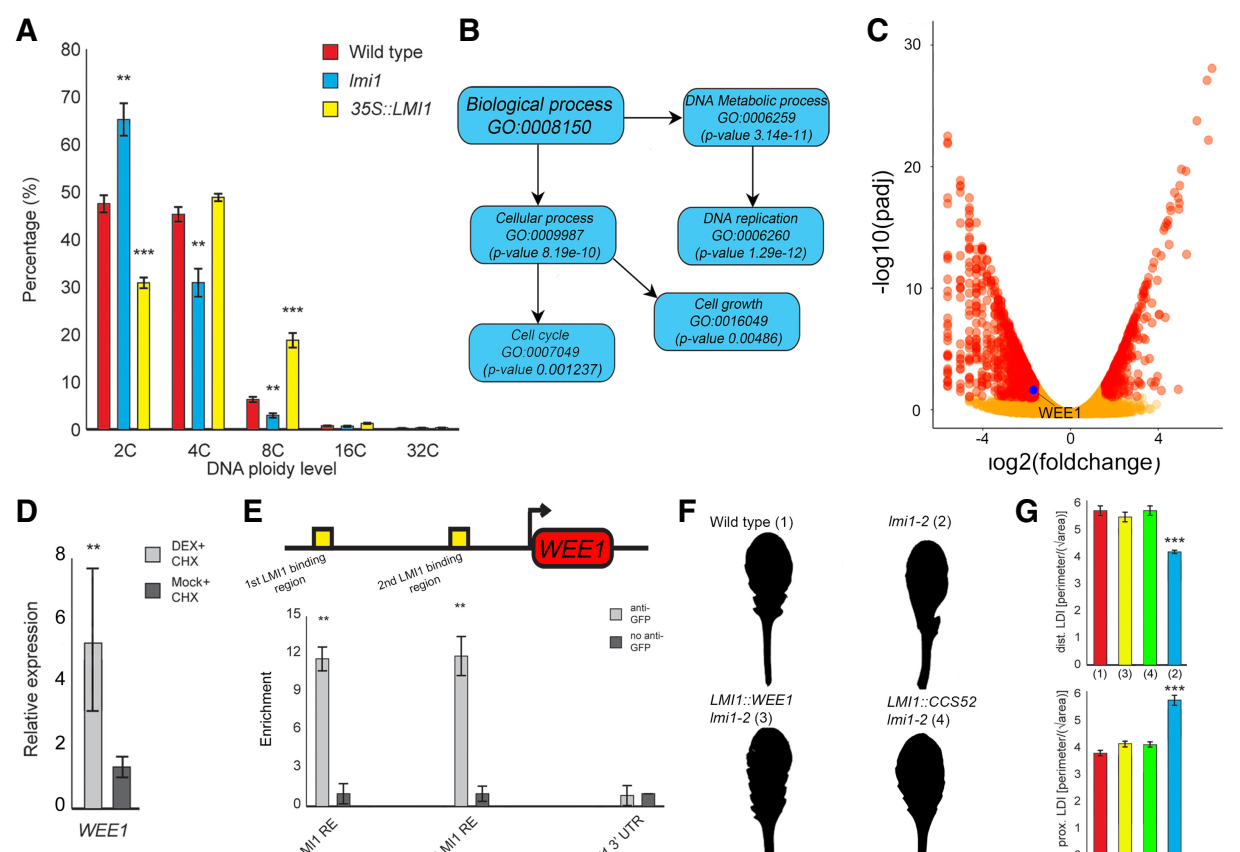

E
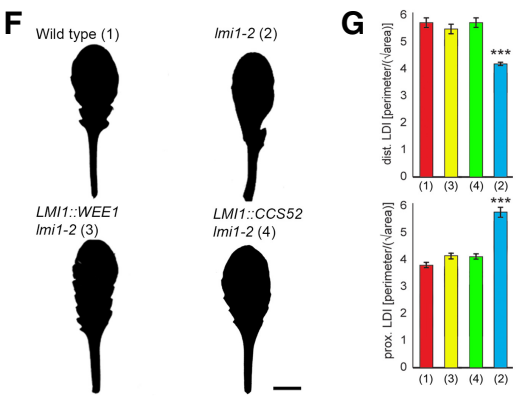

Figure 3. LMI1 promotes endoreduplication by activating WEE1 expression. (A) Ploidy analysis by flow cytometry in wild-type (red), Imi1-2 (blue), and 35S::LMI1 (yellow) leaves. $n=5$. Mean percentage \pm SEM. $\left(^{* *}\right) P<0.01$; $\left(^{* * *}\right) P<0.001$, ANOVA. $(B)$ Subgroup of the GO categories enriched among differentially expressed genes (DEGs) between wild type and lmi1-2, derived from RNA-seq analysis. $n=3$. $(C)$ Volcano plot showing DEGs (red) and non-DEGs (orange) in lmi1-2 compared with wild-type seedlings, and the WEE1 gene with a putative LMI1-binding site (blue). (D) Quantitative RT-PCR (qRT-PCR) of WEE1 expression in Imi1-2;LMI1::LMI1:GR plants treated with dexamethasone (DEX) + cycloheximide $(\mathrm{CHX})$ (gray) or mock $+\mathrm{CHX}$ (dark gray) $3 \mathrm{~h}$ after treatment. $n=3$. Mean \pm SEM. $\left({ }^{* *}\right) P<0.01$, Student's $t$-test. $(E$, top) $W E E 1$ gene model with upstream regions containing putative LMIl-binding sequences marked in yellow. The arrow indicates transcription start. (Bottom) ChIPqRT-PCR (chromatin immunoprecipitation [ChIP] combined with qRT-PCR) after anti-GFP (gray) or control IgG (dark gray) pull-down in LMI1::LMI1:VENUS shows significant association of LMI1 with chromatin in regions containing the putative binding sites. $n=3$. Mean \pm SEM. $\left({ }^{* *}\right) P<0.0$, Student's $t$-test1. WEE1 $3^{\prime}$ untranslated region (UTR) was used as negative control. (F) Silhouettes of leaf 11 in wild-type, Imi1-2, Imi1-2;LMI1::WEE1, and lmi1-2;LMI1::CCS52 plants. $n=15$ T2 lines. (G) Dissection indices of the distal domain (top graph) and proximal domain (bottom graph) in the lines in $F$, with relative numbers matching the ones in $F . n=10$, each line. Bar, $1 \mathrm{~cm}$.

compensated for by the subsequent endoreduplicationdriven increase in cell size. Therefore, the exclusion of LMI1 from the proximal leaf margin (Fig. 1E,F), a highly proliferative region (Kuchen et al. 2012; Vlad et al. 2014), should be crucial to maintain the correct size and shape of $A$. thaliana leaves. Specifically, the model predicts a reduction in final leaf size if endoreduplication is activated very early in this region of the leaf margin. To directly test this prediction, we fused $L M I 1$ to three different promoters that express both earlier and more proximally than $L M I 1$ in the leaf margin (RCO and CUC2) and throughout the leaf primordium (ASYMMETRIC LEAVES1 [AS1]) (Bilsborough et al. 2011; Hasson et al. 2011; Vlad et al. 2014). Leaf size was dramatically reduced in RCO::LMI1 (Vuolo et al. 2016), CUC2::LMI1, and AS1::LMI1 plants (Supplemental Fig. 10). In particular, AS1::LMI1 plants produced small bladeless leaves followed by arrested development (Supplemental Fig. 10C). These observations support the model predictions and highlight the importance of the precise regulation of LMI1 for attaining correct leaf form.

To understand whether LMI1 function is conserved between plants with different leaf shapes, we used an artificial microRNA (amir-LMI1) to silence expression of the orthologous LMI1 gene in Cardamine hirsuta, a relative of $A$. thaliana with dissected leaves (Hay and Tsiantis 2006). Fully dissected leaves replaced stipules in these transgenic plants (Fig. 4C-F; Supplemental Fig. 11), indicating that LMI1 function is conserved between crucifers with simple and dissected leaves. Furthermore, stipules of amiR-LMI1;rco plants were converted to simplified $r c o-$ like mutant leaves (Fig. 4G,H; Vlad et al. 2014). Therefore, LMI1 and RCO, which are tandemly duplicated genes, largely function divergently in the leaf, consistent with their distinct expression domains (Vlad et al. 2014). Our findings also raise the possibility that evolutionary tinkering with the LMI1 endoreduplication module, as described here, may underlie stipule transformations into leaf-like organs that are typical of many taxa (Darwin 1865; Sousa-Baena et al. 2018). For example, Tendrilless (TI; pea $L M I 1$ ) expression in pea leaves is absent from leafy stipules but present in bladeless tendrils, where it causes growth arrest, associated with increased endoreduplication (expression in tendrils) (Supplemental Fig. 12; also shown previously by Hofer et al. 2009). In conclusion, we demonstrated that spatially regulated expression of the LMI1 transcription factor influences organ proportions through an endoreduplication-mediated trade-off between cell and tissue growth. Our findings may help unify our understanding of the control of organ shape across multicellular eukaryotes. For example, in the developing vertebrate limb bud, the transcription factor GLI3R constrains digit size and number by limiting the pool of mesenchymal progenitors through directly repressing $C d k 6$, a 
A

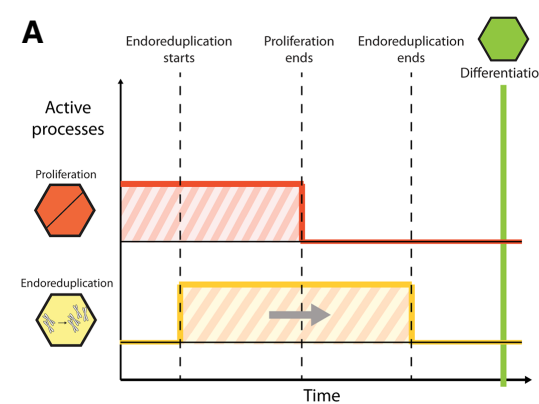

B

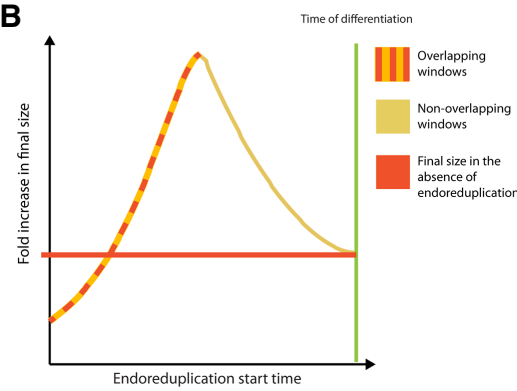

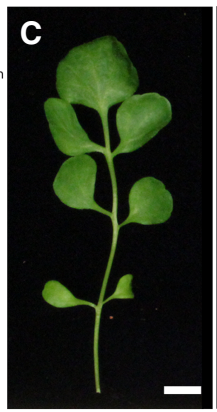
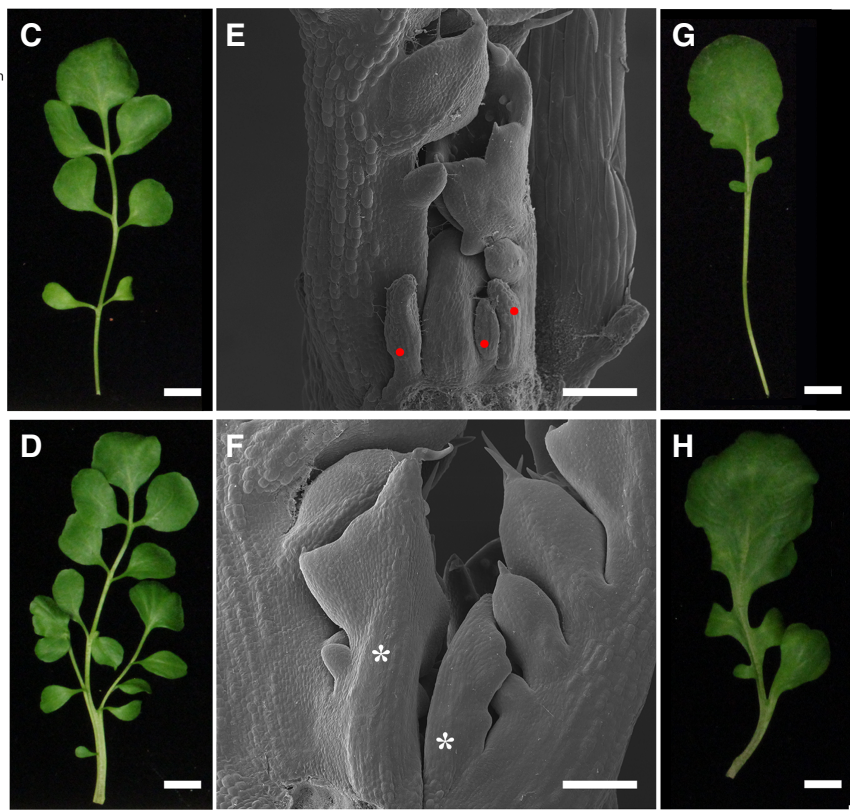

Figure 4. Modeling the regulation of organ size by endoreduplication and conservation of $L M I 1$ function in Cardamine hirsuta. $(A, B)$ Cell population model incorporating proliferation, endoreduplication, and differentiation. $(A)$ The start time for endoreduplication (yellow line) is varied relative to the window of proliferation (orange line), and both processes are terminated by differentiation (green line). (B) Simulations showing fold increase of organ size as a function of endoreduplication start time relative to the size increase produced by proliferation alone (orange line; i.e., when $R_{e}=0$ ). The color of the curve indicates when windows of proliferation and endoreduplication overlap in time (yellow and orange) or occur sequentially (yellow only). $(C-H)$ Leaves of wild-type $(C, E), 35 S:: a m i R-L M I 1(D, F), r c o(G)$, and 35S::amiR-LMI1;rco $(H)$ representative leaf 5 shown for $n=15$ independent lines per genotype. Bars: $C, D, G, H, 1 \mathrm{~cm} ; E, F$ (scanning electron micrographs of developing leaves), $100 \mu \mathrm{m}$. (Red dots) Stipules; (asterisks) ectopic leaves.

regulator of the G1-S cell cycle transition (Lopez-Rios et al. 2012), highlighting the significance of local regulation of the cell cycle for controlling organ proportions. A future challenge will be to determine how broadly the growth trade-off that we identified here is used to control organ form and the degree to which it shaped organ diversity in different animals and plants (e.g., Sicard et al. 2014; Vlad et al. 2014; Andres et al. 2017).

\section{Materials and methods}

Plants were cultivated in growth chambers under long day (16-h light/8-h dark) or short day (8-h light/16-h dark) conditions. A. thaliana and C. hirsuta were transformed using Agrobacterium tumefaciens floral dip transformations as in Hay et al. (2014). Confocal microscopy was performed with a SP8 upright laser scanning confocal microscope with a long working distance water immersion objective (AP 20×/0.8 M27; Zeiss). Statistical analyses were performed with Excel and the R package. Promoter sequence analyses and transcription factor-binding site search were performed with MEME/MAST package. A detailed description of the Materials and Methods is in the Supplemental Material.

\section{Acknowledgments}

We thank Bjorn Pieper for statistical consultation; Soeren Strauss for help with lineage tracing, using code shared by Aleksandra Sapala and Richard Smith, initially published in Barbier de Reuille et al. (2015); L. De Veylder and A. Schnitger for sharing materials and helpful discussions on cell cycle; and the Max Planck Institute for Plant Breeding Research-Genome Centre for RNA-seq. We also acknowledge U. Tartler and R. Berndtgen for technical assistance. This work was supported by Biotechnology and Biological Sciences Research Council grant BB/H011455/1 to M.T., Deutsche Forschungsgemeinschaft MorphoDynamics research unit FOR 2581 to M.T. and A.H., Marie Skłodowska-Curie fellowship IF-2015 703886 to A.R., EMBO Long-Term Fellowship ALTF 502-2015 to R.A.M., and a core grant from the Max Planck Society to M.T.

Author contributions: F.V. performed the majority of experiments. M.H. performed the chromatin immunoprecipitation and contributed to cloning and transgenic line generation. D.K. performed the time-lapse analysis. A.R. designed and wrote the cell population model and, together with D.K., quantified the time-lapse data and conducted lineage tracing. Y.W. constructed vectors and reporters for WEE1 expression and targeted LMI misexpression. D.V. conducted Cardamine experiments. P.H. performed the in situ experiment in Pisum sativum and contributed to imaging. M.D.G. performed the allometry analysis. X.G. analyzed the RNA-seq data. Z.Z. constructed the double mutants for cuc2-3; Imi1-2 and wox3-2; lmi1-2. A.P. provided training and assistance in flow cytometry experiments. R.A.M. conducted statistical analysis and helped with lineage tracing. A.H. contributed to data analysis. F.V., A.H., A.R., R.A.M., and M.T. wrote the manuscript with input from other authors. M.T. designed and directed the study.

\section{References}

Andres RJ, Coneva V, Frank MH, Tuttle JR, Samayoa LF, Han SW, Kaur B, Zhu L, Fang H, Bowman DT, et al. 2017. Modifications to a LATE MERISTEM IDENTITY1 gene are responsible for the major leaf shapes of Upland cotton (Gossypium hirsutum L.). Proc Natl Acad Sci 114: E57-E66.

Bar M, Ori N. 2014. Leaf development and morphogenesis. Development 141: 4219-4230.

Barbier de Reuille P, Routier-Kierzkowska AL, Kierzkowski D, Bassel GW, Schupbach T, Tauriello G, Bajpai N, Strauss S, Weber A, Kiss A, et al. 2015. MorphoGraphX: a platform for quantifying morphogenesis in 4D. Elife 4: 05864.

Bilsborough GD, Runions A, Barkoulas M, Jenkins HW, Hasson A, Galinha C, Laufs P, Hay A, Prusinkiewicz P, Tsiantis M. 2011. Model for the 
regulation of Arabidopsis thaliana leaf margin development. Proc Nat1 Acad Sci 108: 3424-3429.

Bramsiepe I, Wester K, Weinl C, Roodbarkelari F, Kasili R, Larkin JC, Hulskamp M, Schnittger A. 2010. Endoreplication controls cell fate maintenance. PLoS Genet 6: e1000996.

Cebolla A, Vinardell JM, Kiss E, Olah B, Roudier F, Kondorosi A, Kondorosi E. 1999. The mitotic inhibitor ccs52 is required for endoreduplication and ploidy-dependent cell enlargement in plants. EMBO J 18: 44764484.

Chevalier C, Nafati M, Mathieu-Rivet E, Bourdon M, Frangne N, Cheniclet C, Renaudin JP, Gévaudant F, Hernould M. 2011. Elucidating the functional role of endoreduplication in tomato fruit development. Ann Bot 107: 1159-1169. doi:10.1093/aob/mcq257

Cookson SJ, Van Lijsebettens M, Granier C. 2005. Correlation between leaf growth variables suggest intrinsic and early controls of leaf size in Arabidopsis thaliana. Plant Cell Environ 28: 1355-1366.

Darwin C. 1865. On the movements and habits of climbing plants. Bot $J$ Linn Soc 9: 1-118.

De Schutter K, Joubes J, Cools T, Verkest A, Corellou F, Babiychuk E, Van Der Schueren E, Beeckman T, Kushnir S, Inze D, et al. 2007. Arabidopsis WEE1 kinase controls cell cycle arrest in response to activation of the DNA integrity checkpoint. Plant Cell 19: 211-225.

Franco-Zorrilla JM, López-Vidriero I, Carrasco JL, Godoy M, Vera P, Solano R. 2014. DNA-binding specificities of plant transcription factors and their potential to define target genes. Proc Natl Acad Sci 111: $2367-2372$.

Gonzalez N, Gévaudant F, Hernould M, Chevalier C, Mouras A. 2007. The cell cycle-associated protein kinase WEE1 regulates cell size in relation to endoreduplication in developing tomato fruit. Plant J 51: 642-655. doi:10.1111/j.1365-313X.2007.03167.x

Hasson A, Plessis A, Blein T, Adroher B, Grigg S, Tsiantis M, Boudaoud A, Damerval C, Laufs P. 2011. Evolution and diverse roles of the CUPSHAPED COTYLEDON genes in Arabidopsis leaf development. Plant Cell 23: 54-68.

Hay A, Tsiantis M. 2006. The genetic basis for differences in leaf form between Arabidopsis thaliana and its wild relative Cardamine hirsuta. Nat Genet 38: 942-947.

Hay AS, Pieper B, Cooke E, Mandakova T, Cartolano M, Tattersall AD, Ioio RD, McGowan SJ, Barkoulas M, Galinha C, et al. 2014. Cardamine hirsuta: a versatile genetic system for comparative studies. Plant $J$ 78: $1-15$.

Hofer J, Turner L, Moreau C, Ambrose M, Isaac P, Butcher S, Weller J, Dupin A, Dalmais M, Le Signor C, et al. 2009. Tendril-less regulates tendril formation in pea leaves. Plant Cell 21: 420-428.

Kuchen EE, Fox S, de Reuille PB, Kennaway R, Bensmihen S, Avondo J, Calder GM, Southam P, Robinson S, Bangham A, et al. 2012. Generation of leaf shape through early patterns of growth and tissue polarity. Science 335: 1092-1096.

Lincoln C, Long J, Yamaguchi J, Serikawa K, Hake S. 1994. A knotted1-like homeobox gene in Arabidopsis is expressed in the vegetative meristem and dramatically alters leaf morphology when overexpressed in transgenic plants. Plant Cell 6: 1859-1876.
Lopez-Rios I, Speziale D, Robay D, Scotti M, Osterwalder M, Nusspaumer G, Galli A, Hollander GA, Kmita M, Zeller R. 2012. GLI3 constrains digit number by controlling both progenitor proliferation and BMP-dependent exit to chondrogenesis. Dev Cell 22: 837-848.

Maruyama R, Grevengoed E, Stempniewicz P, Andrew DJ. 2011. Genomewide analysis reveals a major role in cell fate maintenance and an unexpected role in endoreduplication for the Drosophila FoxA gene Fork head. PLoS One 6: e20901.

Massonnet C, Tisne S, Radziejwoski A, Vile D, De Veylder L, Dauzat M, Granier C. 2011. New insights into the control of endoreduplication: endoreduplication could be driven by organ growth in Arabidopsis leaves. Plant Physiol 157: 2044-2055.

Melaragno JE, Mehrotra B, Coleman AW. 1993. Relationship between endopolyploidy and cell size in epidermal tissue of Arabidopsis. Plant Cell 5: 1661-1668.

Rast-Somssich MI, Broholm S, Jenkins H, Canales C, Vlad D, Kwantes M, Bilsborough G, Dello Ioio R, Ewing RM, Laufs P, et al. 2015. Alternate wiring of a KNOXI genetic network underlies differences in leaf development of A. thaliana and C. hirsuta. Genes Dev 29: 2391-2404.

Roeder AH, Cunha A, Ohno CK, Meyerowitz EM. 2012. Cell cycle regulates cell type in the Arabidopsis sepal. Development 139: 4416-4427.

Saddic LA, Huvermann B, Bezhani S, Su Y, Winter CM, Kwon CS, Collum RP, Wagner D. 2006. The LEAFY target LMIl is a meristem identity regulator and acts together with LEAFY to regulate expression of CAULIFLOWER. Development 133: 1673-1682.

Shimizu R, Ji J, Kelsey E, Ohtsu K, Schnable PS, Scanlon MJ. 2009. Tissue specificity and evolution of meristematic WOX3 function. Plant Physiol 149: 841-850.

Sicard A, Thamm A, Marona C, Lee YW, Wahl V, Stinchcombe JR, Wright SI, Kappel C, Lenhard M. 2014. Repeated evolutionary changes of leaf morphology caused by mutations to a homeobox gene. Curr Biol 24: 1880-1886.

Sinnott EW, Bailey IW. 1914. Investigations on the phylogeny of the angiosperms. 3. Nodal anatomy and the morphology of stipules. Am J Bot 1: 441-453.

Sousa-Baena MS, Lohmann LG, Hernandes-Lopes I, Sinha NR. 2018. The molecular control of tendril development in angiosperms. New Phytol 218: 944-958.

Szymanski DB, Marks MD. 1998. GLABROUS1 overexpression and TRIPTYCHON alter the cell cycle and trichome cell fate in Arabidopsis. Plant Cell 10: 2047-2062.

Vlad D, Kierzkowski D, Rast MI, Vuolo F, Dello Ioio R, Galinha C, Gan X, Hajheidari M, Hay A, Smith RS, et al. 2014. Leaf shape evolution through duplication, regulatory diversification, and loss of a homeobox gene. Science 343: 780-783.

Vuolo F, Mentink RA, Hajheidari M, Bailey CD, Filatov DA, Tsiantis M. 2016. Coupled enhancer and coding sequence evolution of a homeobox gene shaped leaf diversity. Genes Dev 30: 2370-2375.

Walker JD, Oppenheimer DG, Concienne J, Larkin JC. 2000. SIAMESE, a gene controlling the endoreduplication cell cycle in Arabidopsis thaliana trichomes. Development 127: 3931-3940. 


\section{CORRIGENDUM}

Genes \& Development 32: 1361-1366 (2018)

\section{Corrigendum: LMI1 homeodomain protein regulates organ proportions by spatial modulation of endoreduplication}

Francesco Vuolo, Daniel Kierzkowski, Adam Runions, Mohsen Hajheidari, Remco A. Mentink, Mainak Das Gupta, Zhongjuan Zhang, Daniela Vlad, Yi Wang, Ales Pecinka, Xiangchao Gan, Angela Hay, Peter Huijser, and Miltos Tsiantis

In the above-mentioned article, we inadvertently omitted two references central to the arguments: Gonzalez et al. (2007) and Chevalier et al. (2011). Both have now been added to the paper, which has been updated online, and can be found on pages 1362 and 1363 in the sentences beginning, "One of the key cell cycle genes showing..." and "However, these findings are in contrast to previous reports...," respectively.

\section{References}

Chevalier C, Nafati M, Mathieu-Rivet E, Bourdon M, Frangne N, Cheniclet C, Renaudin JP, Gévaudant F, Hernould M. 2011. Elucidating the functional role of endoreduplication in tomato fruit development. Ann Bot 107: 1159-1169. doi:10.1093/aob/mcq257

Gonzalez N, Gévaudant F, Hernould M, Chevalier C, Mouras A. 2007. The cell cycle-associated protein kinase WEE1 regulates cell size in relation to endoreduplication in developing tomato fruit. Plant J 51: 642-655. doi:10.1111/j.1365-313X.2007.03167.x

doi: $10.1101 /$ gad.323733.118 


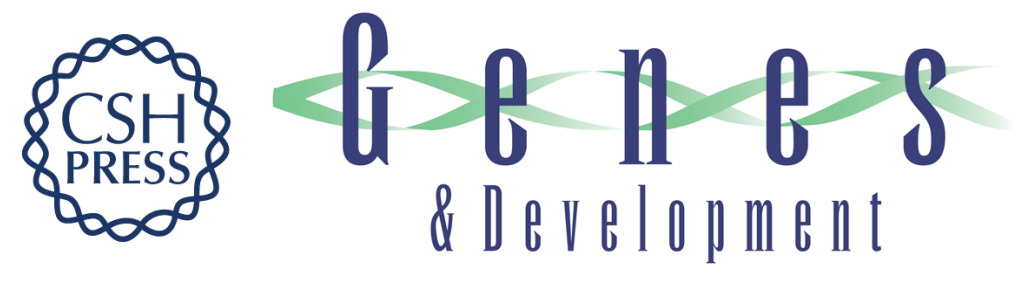

\section{LMI1 homeodomain protein regulates organ proportions by spatial modulation of endoreduplication}

Francesco Vuolo, Daniel Kierzkowski, Adam Runions, et al.

Genes Dev. 2018, 32: originally published online October 26, 2018

Access the most recent version at doi:10.1101/gad.318212.118

\section{Supplemental http://genesdev.cshlp.org/content/suppl/2018/10/26/gad.318212.118.DC1 \\ Material}

Related Content Corrigendum: LMI1 homeodomain protein regulates organ proportions by spatial modulation of endoreduplication

Francesco Vuolo, Daniel Kierzkowski, Adam Runions, et al.

Genes Dev. March , 2019 33: 377

References This article cites 31 articles, 20 of which can be accessed free at:

http://genesdev.cshlp.org/content/32/21-22/1361.full.html\#ref-list-1

Articles cited in:

http://genesdev.cshlp.org/content/32/21-22/1361.full.html\#related-urls

Creative This article, published in Genes \& Development, is available under a Creative Commons

Commons License (Attribution 4.0 International), as described at

License http://creativecommons.org/licenses/by/4.0/.

Email Alerting Receive free email alerts when new articles cite this article - sign up in the box at the top Service right corner of the article or click here.

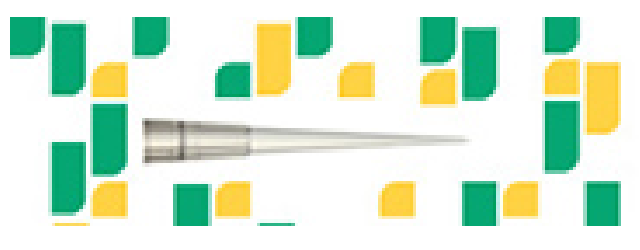

Focused on your science. 